\title{
DISEMINASI PENGEMBANGAN SAFETY INDUCTION VIDEO BERBASIS FLIP LEARNING DI SMK NEGERI 2 SURAKARTA
}

\author{
Wahyu Noviansyah, A.G Tamrin, Roemintoyo, Waluyo, Lilis Trianingsih \\ Program Studi Pendidikan Teknik Bangunan, Universitas Sebelas Maret Surakarta, \\ Indonesia \\ wahyunoviansyah@staff.uns.ac.id
}

\begin{abstract}
Vocational High School (SMK) Negeri 2 Surakarta is located in the Surakarta Municipality, Central Java Province. SMKN 2 Surakarta is one of the vocational education institutions that has a role in producing educated and trained workforce candidates in the field of building engineering expertise. The development of student skills as a prospective workforce requires interaction with machine tools in implementing work practices in wood construction workshops. It is important to introduce occupational safety into work practices in workshops for students in order to avoid the risk of work accidents. So far, the introduction of work safety is still carried out by lecturing methods and has not provided a real vision of the application of work safety in workshops. On the other hand, work safety induction requires the role of video-based learning media that can help students understand work safety material with real illustrations, easy to understand and repeat and interactive. Through digital-based media students can learn the application of work safety independently, not bound by space and time before starting practical implementation. Therefore, the PKM team from the Building Engineering Education Study Program (PTB) intends to disseminate the results of development research in the form of safety induction video learning media to increase understanding and awareness of work safety in workshops for vocational students in the field of building engineering expertise.
\end{abstract}

Keywords: Dissemination, Safety Induction, Flip Learning

\begin{abstract}
Abstrak
Sekolah Menengah Kejuruan (SMK) Negeri 2 Surakarta terletak di wilayah Kotamadya Surakarta, Provinsi Jawa Tengah. SMKN 2 Surakarta adalah sal salah satu lembaga pendidikan kejuruan yang memiliki peran dalam menghasilkan calon tenaga kerja terdidik dan terlatih dalam bidang keahlian teknik bangunan. Pengembangan skill siswa sebagai calon tenaga kerja membutuhkan interaksi dengan mesin-mesin perkakas dalam pelaksanaan praktik kerja di bengkel konstruksi kayu. Pengenalan keselamatan kerja dalam praktik kerja di bengkel penting untuk dilakukan kepada siswa agar dapat menghindari resiko terjadinya kecelakaan kerja. Selama ini pengenalan keselamatan kerja masih dilakukan dengan metode ceramah dan belum memberikan visualiasi yang nyata tentang penerapan keselamatan kerja di workshop. Sebaliknya, induksi keselamatan kerja membutuhkan peran media pembelajaran berbasis video yang dapat membantu siswa untuk memahami materi keselamatan kerja dengan ilustrasi yang nyata, mudah dipahami dan diulang kembali serta interaktif. Melalui media berbasis digital siswa dapat mempelajari penerapan keselamatan kerja secara mandiri, tidak terikat ruang dan waktu sebelum memulai pelaksanaan praktik. Oleh karena itu, tim PKM dari Program Studi Pendidikan Teknik Bangunan (PTB) bermaksud untuk melakukan diseminasi hasil penelitian pengembangan berupa media pembelajaran safety induction video untuk meningkatkan pemahaman dan kesadaran tentang keselamatan kerja di bengkel (workshop) bagi siswa SMK bidang keahlian teknik bangunan.
\end{abstract}

Kata Kunci: Diseminasi, Safety Induction, Flip Learning

Submitted: $2020-09-14 \quad$ Revised: $2020-10-02$ Accepted: $2020-10-05$ 


\section{Pendahuluan}

Kecelakaan kerja merupakan fenomena yang terus terjadi dan belum menunjukkan tanda-tanda penuruan di dunia kerja. Berdasarkan data yang diumumkan oleh Badan Penyelenggara Jaminan Sosial (BPJS) Ketenagakerjaan melalui situs resminya pada tahun 2019, bahwa angka kecelakaan kerja menunjukkan peningkatan dari tahun 2017 sebanyak 123.041 kasus dan tahun 2018 naik menjadi 173.105 kasus.

Pencegahan kecelakaan kerja melalui safety induction pada prinsipnya dilakukan agar pekerja melakukan tindakan yang aman saat bekerja sehingga dapat mencegah kecelakaan kerja. Hal itu sejalan dengan teori Domino Heinrich yang memfokuskan perhatian pada faktor tindakan tidak aman untuk dihilangkan sebagai upaya untuk menghindari kecelakaan dan cedera kerja. Konsep safety induction juga sejalan dengan pemikiran berbagai teori yang memusatkan pada faktor manusia sebagai upaya pengendalian kecelakaan kerja. Para pekerja yang diberikan pengenalan K3 diharapkan dapat memahami dan melaksanakan penerapan standar K3 dengan tertib, cermat dan bersungguh-sungguh sehingga resiko kecelakaan kerja dapat dihindari.

Penerapan safety induction seyogyanya tidak hanya dilakukan di lingkungan kerja industri tetapi perlu dimulai di lingkungan pendidikan, khususnya pendidikan vokasional. Pendidikan vokasional sebagai pendidikan yang berorientasi dunia kerja tentu perlu mengenalkan Keselamatan dan Kesehatan Kerja (K3) secara praksis sesuai dengan pengembangan bidang pekerjaan masing-masing. Penggunaan workshop sebagai laboratorium pembentukan skill kerja membutuhkan pengenalan keselamatan dan kesehatan kerja (Safety Induction) untuk menghindari dan meminimalisir terjadinya kecelakaan kerja.

Paparan tentang fenomena kecelakaan kerja memperkuat asumsi bahwa urgensi pengenalan Keselamatan dan Kesehatan Kerja (K3) perlu dilakukan sebagai solusi korektif dan preventif dalam merespon fenomena kecelakaan kerja. Pengembangan Safety Induction Video berbasis Flip Learning diharapkan dapat menjadi media pendukung dalam penerapan K3 di lingkungan workshop yang menyesuaikan pendekatan karakteristik pembelajaran abad 21 berbasis ICT dan menerapkan konsep merdeka belajar bagi siswa SMK, yaitu belajar tidak dibatasi oleh ruang dan waktu. Atas dasar tersebut, perlu dilaksanakan kegiatan pengabdian tentang "Diseminasi Safety Induction Video Berbasis Flip Learning Bagi Guru dan Siswa SMK".

Kegiatan pengabdian ini berlandaskan pada permasalahan yang terjadi di SMK Mitra meliputi: (1) pengenalan keselamatan kerja belum dilakukan dengan media visualiasi yang konkrit; (2) kurangnya kesadaran dalam menerapkan keselamatan kerja saat melakukan praktik di bengkel kerja (workshop); (3) siswa perlu dibekali materi keselamatan kerja dengan media yang menarik, aplikatif, mudah dipelajari secara mandiri, dan mudah untuk diulang.

Berdasarkan permasalahan tersebut maka kegiatan pengabdian ini bertujuan untuk: (1) meningkatkan pemahaman tentang keselamatan kerja di bengkel (workshop) saat melakukan praktik kerja konstruksi kayu; (2) meningkatkan pemahaman tentang jenis jenis kecelakaan kerja; (3) meningkatkan pemahaman tentan prosedur tanggap darurat saat bencana dan kecelakaan kerja; (4) meningkatkan pemahaman fungsi dan 
penerapan Alat Pelindung Diri (APD); (5) meningkatkan pemahaman tentang penerapan $\mathrm{K} 3$ saat mengoperasikan mesin perkakas.

\section{Metode}

Kegiatan pengabdian masyarakat dilakukan di Sekolah Menengah Kejuruan (SMK) Negeri 2 Surakarta. Kegiatan ini melibatkan Tim Dosen Prodi Pendidikan Teknik Bangunan, guru dan siswa SMK Negeri 2 Surakarta dan SMK Negeri 5 Surakarta. Pengabdian masyarakat di SMK Negeri 2 ini terdiri dari beberapa tahapan kegiatan, yaitu: (1) pra-lapangan; (2) pelaksanaan lapangan; (3) pasca lapangan. Rincian tahapan kegiatan dapat dilihat sebagai berikut.

Tabel 1. Tahap Pra-Lapangan

\begin{tabular}{|c|c|}
\hline Tahapan & Keterangan \\
\hline Focus Group Discussion & $\begin{array}{l}\text { Kegiatan ini dilakukan untuk mendiskusikan terkait permasalahan } \\
\text { yang terjadi di SMK Mitra dan mencarikan solusi pengembangan } \\
\text { media induksi keselamatan kerja }\end{array}$ \\
\hline Pembentukan Tim Pengabdi & $\begin{array}{l}\text { Membentuk Tim Pengabdi yang terdiri dari mahasiswa dan dosen } \\
\text { serta pembagian tugas masing-masing anggota tim }\end{array}$ \\
\hline $\begin{array}{l}\text { Penyusunan dan pengajuan } \\
\text { Proposal }\end{array}$ & $\begin{array}{l}\text { Melakukan penyusunan proposal untuk mengajukan solusi } \\
\text { permasalah mitra dan pendanaan kegiatan pengabdian }\end{array}$ \\
\hline $\begin{array}{l}\text { Koordinasi Tim Pengabdi dan } \\
\text { SMK Mitra }\end{array}$ & $\begin{array}{l}\text { Melakukan koordinasi bersama mitra tentang jadwal pelaksanaan } \\
\text { dan teknis kegiatan }\end{array}$ \\
\hline $\begin{array}{l}\text { Persiapan bahan dan alat } \\
\text { diseminasi }\end{array}$ & $\begin{array}{l}\text { Menyiapkan bahan dan alat yang dibutuhkan untuk kegiatan } \\
\text { diseminasi produk hasil penelitian }\end{array}$ \\
\hline
\end{tabular}

Tabel 2. Tahap Pelaksanaan Lapangan

\begin{tabular}{|c|c|}
\hline Tahapan & Keterangan \\
\hline Orientasi & $\begin{array}{l}\text { Pada tahap ini dilakukan kegiatan pengenalan keselamatan kerja } \\
\text { di workshop dan konsep media pembelajaran safety induction } \\
\text { video yang dikembangkan oleh Tim Pengabdi. }\end{array}$ \\
\hline Simulasi & $\begin{array}{l}\text { Pada tahap ini dilakukan simulasi penggunaan media } \\
\text { pembelajaran safety induction Video dengan menggunakan } \\
\text { metode pembelajaran flip learning }\end{array}$ \\
\hline Pelatihan dan pendampingan & $\begin{array}{l}\text { Pada tahap ini guru dan siswa SMK Mitra melakukan ujicoba } \\
\text { operasional media safety induction video. }\end{array}$ \\
\hline Assesmen & $\begin{array}{l}\text { Melakukan penilaian produk dari pengguna (guru dan siswa) } \\
\text { melalui angket yang didistribusikan saat pengabdian. }\end{array}$ \\
\hline
\end{tabular}

Tabel 3. Tahap Pasca Lapangan

\begin{tabular}{ll}
\hline \multicolumn{1}{c}{ Tahapan } & \multicolumn{1}{c}{ Keterangan } \\
\hline Evaluasi & Kegiatan evaluasi dilakukan dengan menganalisis hasil pengisian \\
& $\begin{array}{l}\text { kuisioner oleh guru dan siswa dari SMK Mitra dengan statistik } \\
\text { deskriptif. } \\
\text { Kencana Tindak Lanjut } \\
\text { Kegiatan ini dilakukan sebagai hasil refleksi dari evaluasi yang } \\
\text { telah dilakukan untuk menyusun rencana kegiatan lanjutan. }\end{array}$ \\
\hline
\end{tabular}




\section{Hasil dan Pembahasan}

Pengenalan keselamatan kerja sangat urgen untuk dilakukan kepada siswa SMK yang notabene belum memahami secara utuh mengenai situasi dan kondisi bengkel kerja (workshop). Pemberian pengetahuan tentang K3 diharapkan siswa dapat menerapkan praktik keselamatan kerja dengan benar dan aman. Hal itu dikarenakan terdapat hubungan positif antara pengetahuan tentang K3 dengan prestasi praktik (Tirta, 2011). Dengan demikian, resiko dan potensi bahaya kecelakaan kerja dapat dihindari dan diminimalisir sedini mungkin.

Pengabdian masyarakat ini bertujuan untuk meningkatkan pemahaman guru dan siswa Sekolah Menengah Kejuruan (SMK) bidang keahlian teknik bangunan tentang keselamatan kerja saat melakukan praktik kerja konstruksi kayu di workshop. Kegiatan pengabdian masyarakat dilakukan di SMK Negeri 2 Surakarta pada hari selasa, 8 September 2020 di Ruang Aula SMK Negeri 2 Surakarta. Kegiatan ini melibatkan beberapa pihak yaitu: Program Studi Pendidikan Teknik Bangunan, Fakultas Keguruan dan Ilmu Pendidikan, Universitas Sebelas Maret (UNS) Surakarta, Sekolah Menengah Kejuruan Negeri (SMKN) 5 Surakarta dan Sekolah Menengah Kejuruan Negeri (SMKN) 2 Surakarta. Tim pengabdi dari Program Studi Pendidikan Teknik Bangunan berperan sebagai pengembang media pembelajaran safety induction video berbasis flip learning. Sementara guru dan siswa dari SMK Negeri 5 dan 2 Surakarta berperan sebagai peserta.

Diseminasi media pembelajaran tentang induksi keselamatan kerja bermanfaat untuk mencegah dan menghindari resiko terjadinya kecelakaan kerja saat kegiatan praktik di workshop SMK bidang keahlian teknik bangunan. Dengan pemahaman yang utuh serta disertai ilustrasi yang nyata maka siswa akan cenderung berhati-hati dalam bekerja dan mengoperasikan mesin perkakas.

Kegiatan pelaksanaan pengabdian dilakukan dengan beberapa tahapan kegiatan, antara lain:

a. Melakukan pemaparan tentang hasil produk penelitian pengembangan tentang safety induction video berbasis flip learning

b. Membagikan bahan (file) media pembelajaran yang dapat diunduh oleh peserta dari lembaga mitra melalui laman: http://bit.ly/media_siv

c. Menjelaskan konsep media pembelajaran safety induction video berbasis flip learning

d. Melakukan pelatihan cara mengoperasikan media pembelajaran safety induction kepada guru dan siswa SMK Mitra

e. Memberikan buku panduan diseminasi tentang petunjuk operasional media pembelajaran safety induction kepada guru dan siswa SMK Mitra

f. Melakukan pengumpulan data melalui angket sebagai bahan evaluasi kegiatan.

Adapun dokumentasi pelaksanaan kegiatan pengabdian masyarakat dalam rangka diseminasi pengembangan safety induction video sebagai berikut. 

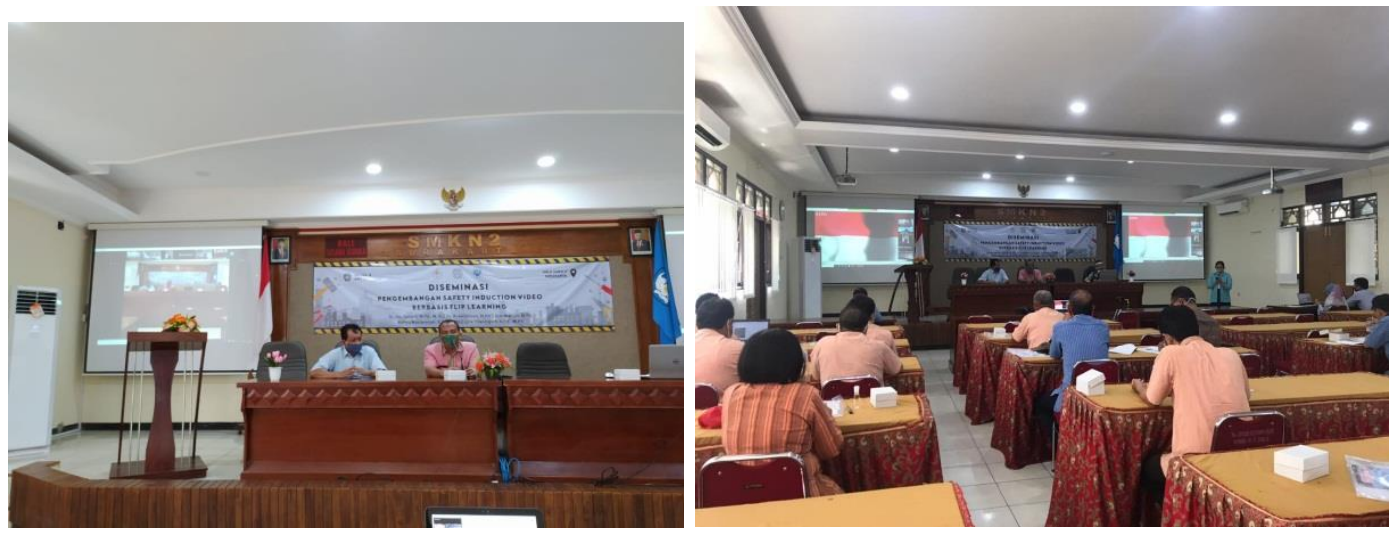

Gambar 1. Tahap Orientasi

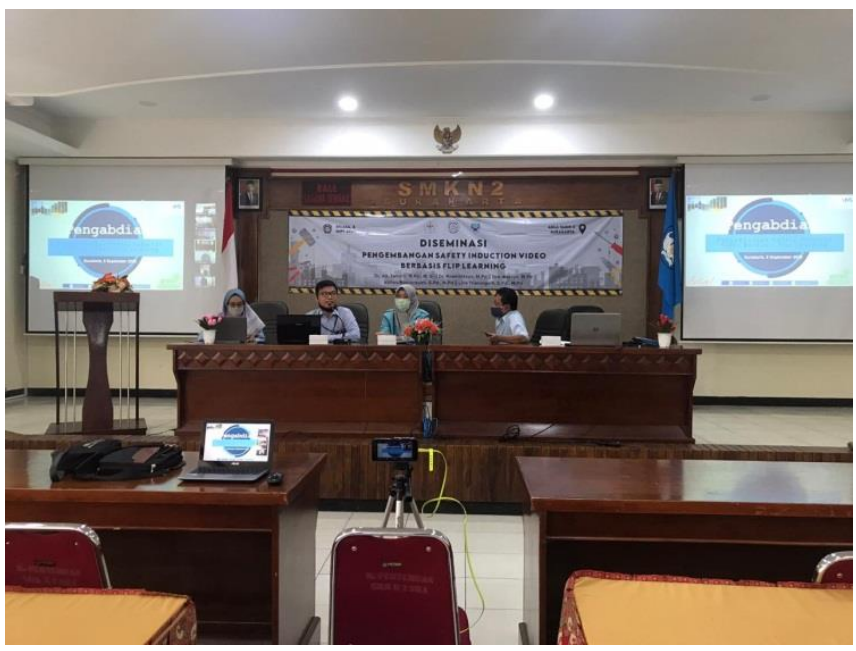

Gambar 2. Pelatihan dan pendampingan operasional media

Selama ini kegiatan induksi keselamatan kerja di bengkel workshop umumnya dilakukan melalui metode ceramah saat mendampingi siswa dalam kegiatan pengarahan praktikum. Metode ini masih dianggap belum maksimal dalam memberikan visualisasi yang nyata tentang bagaimana seharusnya siswa bersikap dan berperilaku yang sesuai dengan standar prosedur keselamatan kerja. Dengan begitu metode ini perlu didukung peran media pembelajaran yang membantu memberikan visualiasasi dan demonstrasi mengenai konsep dan penerapan keselamatan kerja di workshop.

Pada konteks diseminasi ini, tim pengabdi melakukan upaya pengenalan suatu inovasi pembelajaran berupa safety induction media. Media ini merupakan bahan ajar elektonik yang mengkombinasikan media visual, audio dan audiovisual. Tujuannya agar dapat mendukung semua karakteristik dah gaya belajar siswa. Media ini memberikan penjelasan mengenai keselamatan dalam cara-cara bekerja di workshop. Tujuannya sejalan dengan yang diungkapkan oleh Suma'mur (1987), yaitu: untuk (1) melindungi tenaga kerja (siswa) atas hak keselamatannya dalam melakukan pekerjaan; (2) menjamin keselamatn setiap orang ditempat kerja.

Pengenalan induksi keselamatan kerja melalui safety induction video dianggap berhasil memberikan kesadaran kepada peserta didik untuk menerapkan standar keselamatan kerja selama praktik di workshop. Hal itu dapat dilihat dari data survei pasca melakukan ujicoba media induksi keselamatan kerja kepada siswa berikut ini. 
BERNAS:

Jurnal Pengabdian Kepada Masyarakat

Tabel 1. Data Hasil Validasi Ahli Media

\begin{tabular}{|c|c|c|c|c|c|c|c|c|c|c|}
\hline \multirow[t]{2}{*}{ No } & \multirow[t]{2}{*}{ Aspek } & \multicolumn{5}{|c|}{ Frekuensi } & \multirow[t]{2}{*}{$\begin{array}{l}\text { Jumlah } \\
\text { Skor }\end{array}$} & \multirow[t]{2}{*}{$\begin{array}{c}\text { Jumlah } \\
\text { Butir }\end{array}$} & \multirow[t]{2}{*}{$\begin{array}{c}\text { Bobot } \\
\text { Maksimal }\end{array}$} & \multirow[t]{2}{*}{$\begin{array}{c}\text { Persentase } \\
\quad(\%)\end{array}$} \\
\hline & & 1 & 2 & 3 & 4 & 5 & & & & \\
\hline 1 & Kejelasan & 0 & 0 & 0 & 6 & 5 & 49 & 1 & 55 & 89,1 \\
\hline 2 & $\begin{array}{l}\text { pemahaman } \\
\text { Jumlah }\end{array}$ & 0 & 0 & 0 & 4 & 7 & $\begin{array}{c}51 \\
100\end{array}$ & $\begin{array}{l}1 \\
2\end{array}$ & $\begin{array}{c}55 \\
110\end{array}$ & $\begin{array}{l}92,70 \\
90,91\end{array}$ \\
\hline
\end{tabular}

Keberhasilan dalam pemecahan masalah penerapan keselamatan kerja dapat dilihat dari data pada tabel 1 . Hasil survei menunjukkan bahwa $92,70 \%$ siswa menganggap bahwa media safety induction video dapat membantu memberikan pemahaman tentang penerapan K3 dalam praktik kerja di workshop. Hal itu dapat diperkuat dengan data yang menunjukkan bahwa 89,1\% siswa menganggap bahwa materi yang ditampilkan dalam media memberikan kejelasan tentang K3. Hal yang menarik juga terlihat dari hasil survey bahwa $100 \%$ siswa menjawab bahwa media safety induction memberikan kesadaran kepada siswa tentang pentingnya keselamatan kerja. Sebagaimana terlihat pada gambar berikut ini.

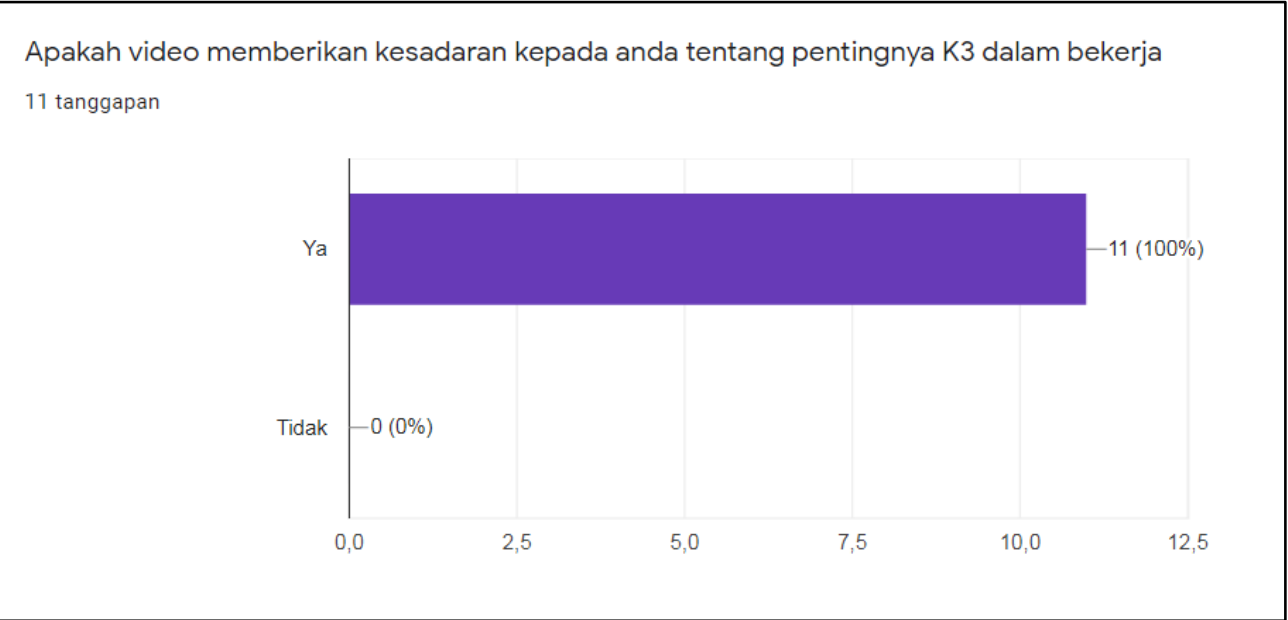

Gambar 3. Survei Pasca Kegiatan PKM

\section{Kesimpulan}

Kegiatan pengabdian dilakukan bertujuan untuk memberikan peningkatan pemahaman tentang induksi keselamatan kerja saat melakukan praktik kerja kayu di lingkungan workshop. Pemahaman keselamatan kerja menjadi penting guna menghindari resiko terjadinya kecelakaan kerja saat praktik. Diseminasi media safety induction video berbasis flip learning bermaksud untuk memfasilitasi peningkatan pemahaman guru dan siswa mengenai standard procedure dan penerapan K3 di workshop. Selain itu, Pengembangan media safety induction yang berbasis flip learning juga bertujuan untuk memudahkan siswa untuk belajar tentang keselamatan kerja secara mandiri, tidak terikat ruang dan waktu serta dapat diulang kembali sesuai tingkat kecepatan siswa dalam memahami materi.

\section{Daftar Pustaka}

Arifin, Z. (2011). Penelitian Pendidikan. Bandung: Remaja Rosda Karya 
Bambang, G. (2006). Kesehatan dan Keselamatan Kerja. Jakarta: UI Press

BPJS Ketenagakerjaan. (2019). Angka Kecelakaan Kerja Cenderung Meningkat, BPJS Ketenagakerjaan Bayar Santunan Rp1,2 Triliun. (https://www.bpjsketenagakerjaan.go.id/berita/23322/Angka-Kecelakaan-KerjaCenderung-Meningkat,-BPJS-Ketenagakerjaan-Bayar-Santunan-Rp1,2-Triliun), diakses 2 September 2020

Hidayat \& Wahyuni. (2016). Kajian Keselamatan dan Kesehatan Kerja Bengkel di Jurusan Pendidikan Teknik Sipil dan Perencanaan Fakultas Teknik UNY. Jurnal Pendidikan Teknologi dan Kejuruan. (online), No.2, (https://doi.org/10.21831/jptk.v23i1.9355), diakses 2 September 2020.

Suma'mur. (1987). Keselamatan Kerja \& Pencegahan Kecelakaan. Jakarta: CV. Haji Masagung.

Tirta, A. (2011). Hubungan Pengetahuan Keselamatan dan Kesehatan Kerja dengan Prestasi Praktik Peserta Diklat Otomotif BLKPP Yogyakarta. Skripsi tidak dipublikasikan, UNY Yogyakarta, (online), (https://eprints.uny.ac.id/22827/1/Andriansyah\%20Tirta\%20-\%20035424027.pdf) diakses 10 September 2020

Ziko, J, M., Lushinga, N \& Akakandelwa, I. (2017). An Evaluastion Effectiveness of Health and Safety Induction Practice in The Zambian Construction Industry. International Journal of Social, Behavioral, Educational, Economic, Business and Industrial Engineering. (online), No.11, (https://pdfs.semanticscholar.org/7f0c/c431cc0b4b7320aa09a39c5ac9edd65cd975.p df), diakses 2 September 2020. 